\title{
Proclamations royales et Indiens au XVIIIe siècle: enjeux politiques et sociaux/
}

\author{
Juras reales e indios en el siglo XVIII: \\ perspectivas políticas y sociales
}

\author{
Thomas Calvo \\ Colegio de Michoacán, México \\ y Université de Paris Ouest-Nanterre, Francia
}

Les honneurs funèbres et les proclamations des souverains ont été un des rites de passage par lesquels la Monarchie hispanique, depuis Charles Quint, s'est manifestée, parfois de forme presque physique. Au long des trois siècles ceci s'est accompagné d'une évolution: en particulier le caractère plus ouvert et plus laïque de la jura fait qu'au temps des Lumières celle-ci prenne plus de relief. Depuis la fin du règne de Charles II s'est opérée une ouverture en faveur de la noblesse indienne. Avec une nouvelle dynastie, ce groupe voit dans la proclamation une possibilité de s'ouvrir un espace de visibilité, où il ne sera plus seulement un comparse. Ceci se fera de manière progressive, distincte: contrôlée dans les capitales, ex-abrupto a Patzcuaro en 1701, réflexive dans les vieilles villes indigènes privilégiées (Tlaxcala). Sur la frontière l'ombre de l'Indien de guerre plane. Le cas de Lima, en 1761, es emblématique. La fête royale participe de l'échec qui devient manifeste en 1808. C'est pour cela que les proclamations de 1809 ont un tout autre visage — plus religieux, plus individualisé.

MoTS-CLÉs: Monarchie hispanique; Amérique espagnole; Cérémonies royales; XVIIIe siècle; Élites indiennes.

Las honras fúnebres y las juras han sido uno de los ritos de paso por los cuales la Monarquía se ha manifestado, desde Carlos $V$, en sus reinos, de forma casi física.Esto se acompaña de una evolución a través de los tres siglos: en particular el carácter más abierto, más seglar de la jura hace que en tiempos de las Luces tome más relieve. Desde fines del reinado de Carlos II hay una apertura a favor de la nobleza india. Con una nueva dinastía, este grupo ve en la jura real la posibilidad de abrirse un espacio de visibilidad, donde ya no será simple comparsa. Esto se dará de forma progresiva, distinta: controlada en las capitales, sorpresiva en Patzcuaro en 1701, más reflexiva en las viejas ciudades indígenas con privilegios (Tlaxcala). En la frontera la sombra del indio de guerra es un elemento clave. El caso de Lima, en 1761, es emblemático. En cierta forma el mensaje real participa del fracaso que se pone de manifiesto en 1808. Por tanto las juras de 1809 toman otro cariz —más religioso, más individualizado.

Palabras ClaVE: Monarquía hispana; América española; Siglo XVIII; Ceremonias reales; Nobleza indígena. 
Señor, esta lealtad se probó segunda vez en el año de 1748 en las plausibles fiestas que en la ciudad de los Reyes, corte del Perú, hicieron vuestros indios en los dias veintiuno, veintidós de febrero. Y habiéndoles cabido en ellas el último lugar como siempre les cabe en todo, no obstante le llevaron el primero en la pública aclamación no vulgar y popular, sino muy cierta, discreta y crítica [...], fueron las más plausibles, lucidas, alegres, grandes, majestuosas, augustas, reales, pomposas, heroicas, suntuosas y magníficas que se han visto en estos dos siglos, y que quedaron arrasadas no sólo las pasadas y presentes que vuestros vasallos los españoles han hecho, si aún en los antiguos tiempos romanos y de todas las naciones. ${ }^{1}$

Issus tout à la fois de prestigieuses dynasties —apparentées à Charlemagne-, et d'un principe plus ou moins affirmé d'éligibilité, l'Empereur et les souverains francs pouvaient, au Moyen Age, asseoir leur légitimité et leur aura sur le sacre. Leurs équivalents castillans, moins assurés, devaient s'imposer contre les autres prétendants et parmi les monarques de la Péninsule. Ils avaient aussi à gagner les combats de la Reconquista. Ainsi le roi de Castille est proche du monarque hellénistique, ou encore du chef de guerre, du caudillo que ses soldats proclament au soir de la victoire. C'est là un des points d'enracinement de la jura, ou proclamation royale en Castille.

Celle-ci s'impose définitivement avec Charles Quint. Il incarnait parfaitement l'image du conquérant, de Tunis à Mexico ou Cuzco: l'iconographie devait le rappeler inlassablement. ${ }^{2}$ Monarque d'un empire maintenant planétaire, ${ }^{3}$ le souverain hispanique faisait de la double cérémonie des honneurs funèbres dus à son prédécesseur et de la proclamation du nouveau règne, ensemble stéréotypé, démultiplié sur toute l'étendue de ses terres, de capitale de royaume en chef-lieu de province, un puissant instrument de cohésion politique. ${ }^{4}$ Pendant près de trois siècles, ce fut le message répété, comme à Lima, en 1666, à l'occasion de la aclamación de Charles II: "Como de la vida el coraçon, es el rey tesoro de los Reynos». ${ }^{5}$

1 Fray Calixto de San José Tupac Inca, 1992, p. 247.

2 Sur son túmulo à Tolède (novembre 1558) apparaissent «unos lienzos de historias que su Magestad hubo en su vida, que eran la ganada de las Indias, la de Túnez y la Goleta, la de Africa, la prisión del rey de Francia en Pavia, la de Viena contra el Turco, lo de Alemania y la coronación de Su Majestad», Relaciones históricas, 1896, pp. 45-46.

3 Philippe II parachève l'œuvre entre 1565 et 1580, avec la conquête des Philippines, puis de la thalassocratie portugaise.

4 La littérature historique sur le thème est infinie, pour une synthèse commode, et pour la Lima du XVIIe siècle, espace et moment de splendeur; voir Osorio, 2004, pp. 447-474.

5 Aclamaciones y pendones que levanto la muy noble y coronada ciudad de Los Reyes, 1666, f. 7 r. 
Cela signifie-t-il que pendant toute cette période, et sur l'ensemble américain, rien ne changea? Ce serait difficilement acceptable. Il y eut des moments décisifs: les honras funèbres de Charles Quint (1558) et de Philippe II (1599) à Mexico seront des modèles pour l'ensemble de l'Empire, presque au même titre que le furent les cérémonies équivalentes de Bruxelles ou Séville. L'année 1701, avec l'avènement de Philippe V et d'une nouvelle dynastie est moins marquante en termes de rituel, mais décisive en matière politique. D'ailleurs les retombées de cette date se font vite sentir, même pour le cérémoniel: l'équilibre entre honras et juras, qui penchait jusque là en faveur des premières, plus sacralisées, servant mieux l'étroite alliance Eglise-Couronne, se rompt au profit de la proclamation, plus ouverte et populaire. Enfin, s'il faut marquer un aboutissement, continental, ce sera 1809 avec le double serment, à Ferdinand VII prisonnier, à la Suprême Junte Centrale qui tente de gouverner en son nom. ${ }^{6}$ On est alors en présence d'un désastre, fruit d'un échec patent de la politique sécularisatrice au long du XVIIIe siècle. D'où un revirement, que le rituel accompagne: retour à l'Eglise et à la sacralité, affirmation du principe d'obéissance corporative et individuelle. Le message politique se durcit alors qu'on bâillonne l'unanimisme qui prenait progressivement le dessus. Bien sûr, le XIXe siècle oscillera encore d'une attitude à l'autre.

C'est donc à «l'ère de la jura», entre 1701 et 1809 que nous nous intéressons, avec quelques précautions. La première est de se rappeler que les honneurs funèbres, bien entendu, subsistent, qu'ils jouent toujours un rôle important, et que les traces qu'ils nous ont laissées sont peut-être plus impressionnantes que jamais. L'oraison funèbre est le morceau de choix, au cœur de la honra; le XVIIIe siècle, en matière d'édition, est largement encore celui du sermon: le nombre d'impressions liées aux honneurs funèbres royaux n'aura jamais été aussi important. Même la modeste communauté de Salta réussit à faire passer à la postérité ceux qu'elle rend en 1747 à Philippe V. Mais, signe des temps, la seconde partie de l'opuscule est consacrée à «l'exaltation» au trône de Ferdinand VI, et sur l'ensemble, la seconde partie occupe les deux tiers du volume. ${ }^{7}$ Symptomatique aussi lorsqu'en 1789-1791, l'oraison funèbre que prononce le puissant archevêque de La Plata (Audience de Charcas) en l'honneur de Charles III reste manuscrite, mais prête à l'impression, alors que le modeste sermon pro-

6 Voir pour la Nouvelle Espagne, Beatriz Rojas (comp.), 2005.

7 Reales exequias. Nous y reviendrons en détail. 
noncé dans le petit Real de Catorze, pour la proclamation de Charles IV, est édité à Mexico. ${ }^{8}$ Tout aussi significatif, lorsque les naturales de Lima prennent sur eux de faire éditer une description des festivités accompagnant la jura de Charles III. Non seulement cette cérémonie et ses descriptions prennent de l'importance, mais on voit apparaître sur le devant de la scène un groupe que l'on croyait davantage spectateur qu'acteur.'

Et c'est ici notre second avertissement. Nous ne nous intéressons pas à la jura en tant que telle, ni même aux transformations qu'elle connaît au XVIIIe siècle, ni à l'ensemble des acteurs. Nous l'avons fait par ailleurs, à l'occasion de la proclamation de Ferdinand VI à Guadalajara en $1747 .{ }^{10} \mathrm{Ce}$ qui nous retient ici, dans un cadre continental, mais avec un moule qui est celui d'un rituel d'origine hispanique, c'est la participation d'un groupe lui-même divers, et ayant en la matière nombre de handicaps: assujetti et d'origine non-hispanique, précisément. Son implication dans le cérémoniel a-t-elle progressé, comme nous le pensons, au long du siècle? Dans quelles circonstances, avec quelles perspectives? Que devient tout ceci lorsque la jura affronte le choc de 1809? Les questions sont simples, les réponses le seront sans doute moins. C'est qu'il y a l'espace qui brouille une partie des conclusions: peut-on attendre la même chose à Lima, à Mexico? Plus encore, les frontières ne sont-elles pas des univers à part? La cohésion communautaire est-elle par ailleurs assez forte pour étouffer, dans ce contexte cérémoniel et festif, les velléités individualistes? Ce serait douteux, dans un contexte où l'évergétisme est si important.

\section{La présence indienne au cours des cérémonies de la dynastie Habsbourg}

Il est enfin une troisième précaution, sur laquelle il n'est guère utile d'insister: bien entendu les Indiens ne furent pas absents des rituels des Habsbourg. Il faut cependant mesurer la portée, et les enjeux de leur participation, pour comprendre le sens des transformations qui s'opèrent à partir de 1701.

8 Oración fúnebre, Biblioteca Nacional de Madrid (BNM), mss. 20067. Peñuelas, 1791, $14 \mathrm{pp}$.

9 Fiestas de los naturales de esta ciudad de Lima.

10 Calvo, otoño de 2005, pp. 67-92. 
Rappelons qu'au cours de cette première période l'attention est centrée sur les honras et l'extraordinaire appareil -le túmulo- que l'on dresse au centre des principales églises. C'est donc dans cet environnement, plus qu'au cours des juras, qu'on détecte la présence ou la participation indigène. Vaincus, les Indiens sont à la fois présentés et sollicités comme tels. Les honras de Charles Quint à Mexico nous éclairent sur ces deux volets. Leur soumission est mise en scène de diverses façons: la plus crue, lorsque l'Empereur est représenté «y D. Hernando Cortés delante de el, armado con la espada desnuda en la mano, y a la par del muchos indios», ${ }^{11}$ la plus subtile avec «muchos indios enlutados con candelas encendidas [...], con los rostros tristes, gran sentimiento por la muerte de Cesar $\gg .{ }^{12}$ Le message politique est énoncé en toute clarté lorsque l'Empereur, assis, le sceptre tendu, «y Montezuma y Atabalita, emperadores en este Nuevo Mundo, hincados de rodillas tendidas las manos tocando en el cetro con rostros alegres». ${ }^{13}$ Quant à leur participation directe, elle fut essentielle, sous forme de travail exigé: «diose orden que en toda la comarca de México se pintasen gran cantidad de escudos imperiales y otras muchas historias y figuras». ${ }^{14}$ Pendant les cérémonies elles-mêmes, cependant, leur rôle fut passif.

A l'occasion des proclamations, quelle que soit alors l'importance de leur rituel, les Indiens pouvaient être davantage sur la scène, même si c'était dans un rôle secondaire. Le Codex de Tlaltelolco permet de mesurer la distance entre les deux cérémonies, sous l'angle indigène. Dans ses dernières planches, ce document — qui date approximativement de 1562 - fait revivre, de façon très contrastée la proclamation de Philippe II (juin 1557) et les honneurs funèbres de Charles Quint à Mexico. La première scène est animée: les autorités espagnoles dominent sur leur estrade, devant eux l'alferez real agite le pendón de Philippe II, et surtout trois chevaliers-aigles et tigres dansent, comme dans les mitotes. Entre ces divers niveaux, quelques représentants de l'aristocratie mexica servent de lien. L'autre cérémonie est simplement suggérée par la représentation, isolée, glacée du túmulo impérial de 1559: le catafalque, en deux corps, où apparaissent la mort en archer, les armes - aigle bicéphale, tour et lion et deux sphères- de Charles Quint. Sur cette scène aucun personnage vivant n'est présenté, aucune participation indienne n'est suggérée.

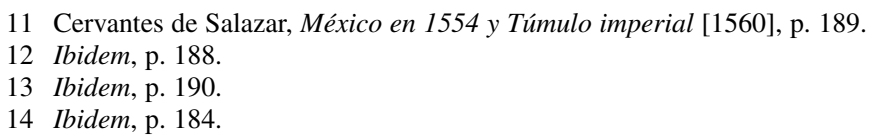


Il est vrai, d'autres documents peuvent être plus explicites, mais toujours ils révèlent que la participation des Indiens est limitée, et plus encore en matière de honras. Domingo Chimalpáhin rappelle qu'au cours de la procession de 1559, les 4 étendards des principales communautés mexicas étaient présents. ${ }^{15}$ Quant au Codex Osuna, il signale crûment que si les quatre barrios de Mexico ont confectionné un catafalque à l'occasion de la mort du vice-roi Velasco (1564) «no se les pagó cosa alguna». ${ }^{16}$ S'agissant des vice-rois encore, leur entrée solennelle peut, par certains côtés, s'apparenter aux proclamations. En tout cas le rôle qui y était dévolu aux Indiens était comparable aux cérémonies d'avénement de Philippe II. En 1550, lorsque Velasco passe par Cholula, «los amaquemecas fueron a recibirlo a Cholollan, y sólo ellos danzaron; ejecutaron el "cantar de las [guerras] chalcas" en honor del [nuevo] virrey». ${ }^{17}$ Surtout l'exhibition de Moctezuma permettait de rappeler la «donation» faite à Charles Quint, comme en 1600, devant le comte de Monterrey, à Mexico encore. ${ }^{18}$

A Puebla, le jour de saint Jacques 1557, eut lieu la jura de Philippe II. Ce fut une cérémonie intense, sobre, centrée sur une succession de serments de fidélité, individuels et collectifs — comme on le retrouvera en 1809. Dans ces conditions tout débordement étant rendu impossible, il n'y eut aucune difficulté à admettre les représentants indiens sur l'estrade, afin qu'en second lieu, et par le biais d'interprètes, ils puissent aussi faire allégeance. Mais pour le chroniqueur du XVIIIe qui transcrit l'acte, la portée de l'ensemble est ailleurs: "confirmaron la rancia, natural lealtad española todos los vecinos de esta angélica ciudad». ${ }^{19}$ En tout cas, par la suite, cette participation directe de l'élite indienne disparaît des proclamations de Puebla au XVIIe siècle. ${ }^{20}$

Et à Lima? Dans son essence hispanique, le cérémonial ne saurait vraiment varié, et on n'a pas à s'y appesantir. La participation indienne, dans l'ensemble, reste dans la même tonalité, si l'on reprend la Aclamación y pendones du 17 octobre 1666, déjà évoquée. La plèbe —et

15 Chimalpahín, 1998, t. II, pp. 211-213.

16 Codice Osuna, 1947, pp. 139-140.

17 Chimalpahín, 1998, t. II, p. 207.

18 Domingo Chimalpahín, 2001, p. 77.

19 López de Villaseñor, 1961, pp. 220-222.

20 Pour celle de Charles II, en 1666, voir Archivo del Ayuntamiento de Puebla. Libro de Cabildo, $\mathrm{n}^{\circ} 26$, fs. $266 \mathrm{v}$ et svts. 
PROCLAMATIONS ROYALES ET INDIENS AU XVIIIE SIÈCLE

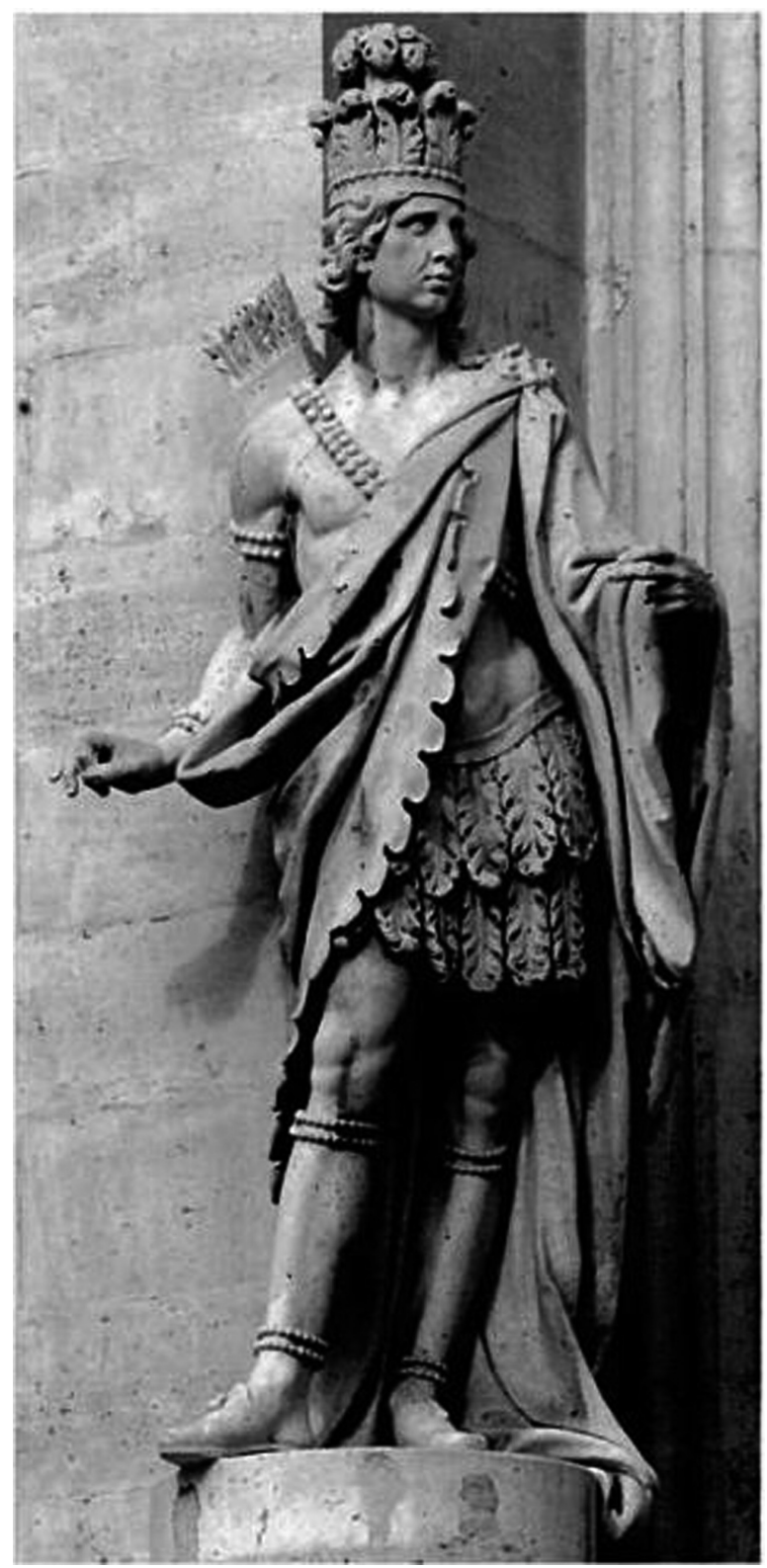

Statue de Moctezuma, Palacio Real de Madrid. 
donc l'essentiel de la population indienne- est étroitement contenue, la place étant entourée d'une palissade (valla) haute de 1,5 varas, "para que el concurso de la gente no estorvasse las operaciones». ${ }^{21}$ Les Indiens eurent-ils une part active? Le texte est ici extrêmement discret. On le devine seulement, à l'énoncé du cortège musical qui accompagne le pendón sur son trajet: «clarines, caxas, atabales, trompetas y chirimías». ${ }^{22}$ Dansèrent-ils? On peut en douter, vu la brièveté de l'ensemble (une courte après-midi). Cependant, ils eurent une participation obligée, sur le monument lui-même, et que la gravure nous restitue. Sous le portrait du jeune Charles II, apparaît «el Inca, en su antiguo traje [...]. Ofreciendo una corona de oro en las manos, y otra de flores la coya que usava de no menos grandeza». ${ }^{23}$ Ainsi, de façon symétrique à ce qu'on rencontre au Mexique, le décor de la jura à Lima met en scène la donation (?) d'Atahualpa. Il est d'ailleurs probable que la très discrète implication indienne ici, en 1666 soit directement liée à la conjoncture. C'est la fin des campagnes d'extirpation des idolâtries, c'est le moment d'un certain nombre de revendications et complots d'essence incaïques, qui annoncent «l'utopie andine» à la recherche de l'Inca. ${ }^{24}$ Dans des circonstances politiques moins tendues, la présence indienne pouvait être beaucoup plus importante, comme à l'occasion des fêtes en l'honneur de la naissance du prince Felipe Próspero, en 1659. ${ }^{25}$

Ces participations, pour exotiques —à nos yeux- et théâtrales qu'elles soient, enfermaient beaucoup d'ambiguïté, voire de frustrations: dans le meilleur des cas, les Indiens étaient réduits à un rôle de comparses flamboyants, dans le pire à une présence de carton-pâte... Même la mise en scène du contrat passé avec la Monarchie - la donation- était orchestrée, médiatisée par l'élite créole: la noblesse indienne, et moins encore la population indigène, n'en tiraient aucun profit. Pouvait-on voir les choses évoluer, à l'occasion du changement de dynastie, en 1701 ?

21 Aclamación y pendones, f. 8v.

22 Ibidem, f. 37r.

23 Ibidem, f. 11.

24 Voir Flores Galindo, 1993 [1988], pp. 102-103, et Périssat, 2002, p. 250.

25 Mugaburú, 1935-1936, T. II, 1936, p. 34.

26 En fait le climat politique, en référence à la noblesse indigène, commence à changer dès l'époque de Charles II. Par une cédule de 1691 on propose des bourses pour l'entrée de caciques dans les collèges tridentins. Suivant cette logique, en 1697 une autre cédule ouvre toutes les charges publiques aux nobles indiens. Tout ceci va impulser la demande d'études supérieures par le groupe au long du XVIIIe siècle. Voir Menegus et Aguirre, 2006, p. 104. 


\section{Les juras de Philippe $\mathrm{V}$ et le «coup de force» des élites indiennes}

En 1701, tout doit se faire rapidement, voire dans l'improvisation. A Mexico, exceptionnellement, le portrait royal, sur l'estrade, est remplacé par une inscription latine: c'était sans doute moins compromettant, plus neutre. On réserve, comme à Lima, l'effigie du souverain pour les salons du palais royal. ${ }^{27}$ A Puebla, on s'emploie d'ailleurs à justifier la précipitation, "para que las noticias de sus reales animos y fieles procederes llegasen quanto antes a los estrados reales» ${ }^{28} \mathrm{Et}$ de fait, on s'acharne à faire connaître les cérémonies et festivités pratiquées pour l'occasion, preuve de l'importance qu'elles revêtent, en ces circonstances mouvantes: pour la seule proclamation de Puebla de 1701, trois relations, au moins, furent imprimées.

On peut penser que dans l'urgence, et avec la montée des pressions politiques, on s'appliqua à permettre le moins d'innovations possibles, notamment venant des plus défavorisés, les Indiens. Sans doute, mais «les temps nouveaux» ouvraient forcément des brèches, que les indigènes s'employèrent à élargir. Ceci était plus difficile dans les capitales vice-royales, où le contrôle était accentué: à Lima, à nouveau, les naturales semblent avoir été totalement exclus du rituel..$^{29} \mathrm{Il}$ en irait de même à Mexico, si le chroniqueur de la proclamation, Gabriel Mendieta Rebollo, ne décrivait pas, incidemment, une scène curieuse: au cœur du rituel «los governadores y caziques dieron libertad a la bulliciosa travesura de varios conejos, liebres y gazapos, que recatados en el embozo de sus tilmas, dando assalto su novedad a la suspension del embelezo, con sus brincos entretuvieron el tablado (en esto más plausible) y movieron a desatarse el gusto en mayores muestras de alborozo».$^{30}$ La péripétie surprend, et pose des questions qui restent sans réponse. Cette innovation était-elle connue, par anticipation, des autorités? Dans le cas contraire, cet intermède «jocoso» aurait été non seulement un clin d'œil de la Nature américaine à l'hommage rendu au souverain hispanique, mais surtout une forme de subversion douce. Les

27 Pour Mexico, voir «Sumptuoso, festivo, real aparato» à la date du 4 avril 1701, et Tovar de Teresa, 1988, t. I, p. 25. Pour Lima, Solemne proclamación y cabalgata real, que el dia 5 de octubre de este año de 1701 hizo la muy noble y Leal ciudad de los Reyes de Lima, levantando pendones por el rey catholico D. Felipe V, Lima 1701, s. p., partiellement reproduit dans Alfonso Mola, 2002, edición en CD, pp. 2154-2158.

28 Noticia de la Real aclamación, s. 1., s. d. [1702], s. p.

29 Du moins à suivre la relation déjà mentionnée, Solemne proclamación y cabalgata.

30 Tovar de Teresa, 1988, t. I, p. 24. 
exclus se rappelaient au bon souvenir des dominants installés sur l'estrade par un geste de dérision ambigu, et pour cela impossible à réprimer.

Dans l'ouest mexicain, les circonstances se révèlent avec plus de netteté. Début mai 1701, la ville de Patzcuaro fête avec fébrilité l'avènement de Philippe V. L'enjeu est important pour elle, car Valladolid, sa cadette hispanique, lui dispute la primauté provinciale. Peut-être est-ce pour cela que la cité indienne tente d'oublier ses origines? Depuis le 1 mai ses élites créoles se livrent à toute une série de joutes opposant Turcs et Espagnols. Au matin du 5 mai, l'alcalde mayor et les autorités municipales se trouvent réunis et s'apprêtent à se rendre sur le tablado et procéder à la jura. Ils sont alors pris de court: «suspendió por entonces su ejecución ver venir el gran concurso de indios naturales por la calle de San Agustin que entra en esta Real Plaza, venian delante de ellos con diversas invenciones y danzas a su usanza de ellos que entretenian [...]. Después de todo se seguía con regio y ostentoso aparato don Miguel de Urbina, cacique, representando la persona del Gran Cazonzi», et accompagné d'une nombreuse suite. Il monta, de sa propre autorité, sur l'estrade, «y puesto de rodillas rindió su corona y cetro a los pies de su Magestad». Ce magistral coup d'éclat réalisé, il s'installa à la place qui lui avait été fixée. ${ }^{31}$ Entre temps, il s'était octroyé une préséance sur les gouvernants espagnols, sans que ceux-ci puissent réagir. Comment discuter une version nouvelle de la «donation» faite au Monarque — cette fois par le Catzonci? Comment s'incommoder de l'intrusion indigène alors même que c'était son passé indien qui légitimait les droits de Patzcuaro sur sa rivale?

A Guadalajara eut lieu une scène encore plus complexe, avec des clivages entrecroisés, qui encore en 1747, à l'occasion de la proclamation de Ferdinand VI, était présente dans les esprits. Les autorités indiennes des deux pueblos (ou barrios), faubourgs de la ville, Analco et Mexicalcingo, réussirent à monter sur l'estrade, avec l'accord des gouvernants espagnols, et elles furent autorisées à prêter publiquement serment. Mais se posa alors le problème de la préséance. Le président de l'Audience trancha avec un jugement de Salomon: les deux communautés crièrent à la fois «Viva el Señor Don Felipe Quinto muchos años», et purent descendre de l'estrade, satisfaites. ${ }^{32}$ D'où aussi le succès que prennent, avec le temps, ces rituels

31 Reproduit dans Enrique Soto González, 1991, p. 23.

32 Bibliothèque Publique de L'Etat de Jalisco (BPEJ), Archivo de la Real Audiencia, C-148-9, Testimonio de la relación de la jura celebrada en esta capital por la exaltación al trono de $S$. M. el Señor Don Fernando Sexto, f. 13r. 
auprès des Indiens (et autres). En 1761, les jésuites se plaignent qu'étant arrivés à Silao le 20 octobre, pour une mission itinérante, «el dia de la comunion de los grandes nos hizieron estos much a falta por haverse venido a las fiestas de la Jura de el Señor Carlos Tercero, que se hizo por aquellos dias en Guanajuato». ${ }^{33}$

Ainsi, il semble bien y avoir eu un éveil de l'appétit de reconnaissance parmi les élites indiennes, même s'il fut largement muselé ici (Lima), énoncé furtivement là (Mexico), dévoyé en d'autres lieux (Guadalajara), mais finalement clairement exprimé ailleurs (Patzcuaro). Les contextes eurent donc leur importance, et «le coup de force» - comme nous l'avons nommé- de Patzcuaro n'est qu'une des possibilités offertes, variables avec la géographie, mais aussi avec le déroulement du siècle.

\section{Mondes de privilèges, mondes de frontières: des participations contrastées}

La gêne, voire la compression ou la frustration que pouvaient encore ressentir en 1701 les élites indiennes de Mexico, Lima, Puebla durant la proclamation n'eurent pas la même dimension dans des espaces où ces aristocraties pouvaient s'honorer d'avantages, voire de privilèges. Mais cela impliquait tout à la fois une histoire prestigieuse, une attitude ambiguë pendant la Conquête, le souci de perpétuer des droits chèrement acquis.

$\mathrm{Au}$ XVIe siècle les ambassades répétées auprès du Souverain permirent aux communautés indiennes de maintenir le lien, de vivifier les relations et acquis. Au XVIIe, comme beaucoup d'autres choses reliées à la Métropole, tout cela fut distendu, se mit à languir, même si demandes, envoyés (procureurs) et cédules royales se croisaient sur l'Atlantique. Dès 1701, la jura, elle-même chargée d'un poids plus lourd, plus expressif, permettait de revitaliser la mémoire, les alliances et les privilèges, et cela au profit de quelques anciennes principautés indiennes.

Le message fut particulièrement clair à Texcoco: il suffit pour en mesurer la portée de transcrire le titre de la relation imprimée de Joseph Francisco de Isla, Buelos de la Imperial aguila tetzcucana. A las radiantes luzes de el luminar mayor de dos espheras [...] D. Phelippe Quinto. ${ }^{34}$ On y

33 Annuas de las missiones, p. 32. 2158-2164.

34 Imprimé à Mexico, 1701, 51 pp. Il, partiellement reproduit par Alfonso Mola, 2002, pp. 
perçoit l'alliance entre l'aigle mexica qui personnifie Texcoco, et l'astre hispanique (et impérial), et que symbolise l'extraordinaire blason donné par Charles Quint à la ville en 1551 —un condensé d'écriture glyphique, et qui est reproduit au revers de la page de titre: ${ }^{35}$ il faut projeter tout cela dans l'éternité, grâce à la célébration, sa relation et l'imprimerie. ${ }^{36}$ Bien entendu Moctezuma et surtout Netzahualcoyotzin sont dans le cortège de la jura, mais surtout les gouverneurs indiens accompagnent la municipalité créole, notamment

\section{Cacique noble Don Gabriel de Ayala Tilma, armador, calzon, viste ropage, Governador actual es (descendiente De Reyes un Pendon lleva eminente.}

Malgré tout, au moment du serment, c'est l'alférez real (espagnol) qui a le rôle déterminant. E peut-on évoquer la récupération du charisme historique de Texcoco vetus par ses élites créoles? En partie.

En la matière l'aristocratie indienne de Tlaxcala avait les reins plus solides, et un art de la mise en scène et de l'auto-valoration plus consommé. Elle sut le démontrer, une fois de plus en 1701. La proclamation sera l'occasion de faire revivre le contrat passé avec la Couronne: après que l'Histoire soit passée par le lac Léthé («centro del mayor olvido»),

oy renace la fama

al generoso incendio de la llama. ${ }^{37}$

Le décor de la proclamation était simple et efficace, sur deux niveaux: en bas une Indienne - personnifiant Tlaxcala — était entourée des quatre chefs de la ville, alliés de Cortés, qui

quatro coronas de oro

offrecian a su alteza con decoro

35 Reproduit dans Tovar de Teresa, 1988, t. I, p. 12.

36 «Su applicación la estara acordando a todos siglos en la temporal eternidad de los moldes [... el autor] haze un servicio obsequioso a su republica describiendo eloquente sus leales efectos, que essa es la ciencia mas provechosa a las ciudades».

37 Fac-simil de En acreditadas observaciones de affectos, con que la muy Noble, Insigne, y Leal Ciudad de Tlaxcala manifesto desempeños [...] en el crecido jubilo a la jura de la Catholica Magestad de nuestro Rey, y Señor Don Phelippe Quinto, Puebla, 1702, dans González Acosta, 2000, pp. 148-149. 
—nouvelle version de la «donation»! Au-dessus se trouvaient les effigies des quatre premiers Philippe rois d'Espagne. Entre les deux ensembles on avait placé le portrait du nouveau roi. ${ }^{38} \mathrm{Si}$ dans le rituel, la première place revient aussi au gouverneur espagnol, qui prête en premier le serment, les élites indigènes ne sont pas cantonnées dans le rôle de simples figurants: le gouverneur tlaxcaltèque -qui accompagne comme son ombre son alter-ego espagnol—, à son tour, brandit l'étendard royal, aux quatre horizons. ${ }^{39}$ Aucun coup de force ne fut nécessaire ici, à la différence de Patzcuaro: les Indiens morts (aux côtés de Cortés) venaient à la rescousse des vivants.

Et cela en plein accord avec les autorités et les élites espagnoles, qui finalement profitaient aussi, dans leurs diverses négociations, de l'aura du passé indigène, du rappel de cette mythique «donation». Que se passait-il, à l'inverse, là où cette histoire ne pouvait pas vivifier le présent, là où les Indiens morts étaient anonymes, ou pire des «barbares»? Les Indiens vivants étaient alors politiquement morts, et les créoles se servaient d'eux comme simple repoussoir, au mieux comme agrément festif. C'est bien entendu les juras sur les frontières que nous évoquons ici. Ces liturgies royales se sont aussi perpétuées dans ces univers depuis le XVIe, sans doute avec moins de moyens, mais peut-être avec plus de force, compte tenu de la mobilisation plus intense des esprits, et d'une militarisation accentuée. ${ }^{40}$ Mais l'accent est alors le plus souvent mis sur les honneurs funèbres, et les descriptions de proclamations restent limitées. ${ }^{41}$

Ainsi en 1711 on prit soin de livrer à l'imprimerie de Mexico la relation de la proclamation que fit Durango, capitale de la Nouvelle Biscaye, au prince des Asturies, le futur Luis I. Outre le manque de moyens que compense «el estremo de amor, y la lealtad» et la tournure tout à fait classique - et hispanique - des festivités (loas, feux d'artifice, combats feints, toros), qu'y apprend-t-on? On fit aussi intervenir, comme note locale, exotique et distinctive tout à la fois, les «escuadras de indios comarcanos», Tepehuanes et Apaches, avec leurs armes et leurs tambours. Ils étaient le rappel des victoires passées, des sacrifices encourus dans la

38 Reales preceptos executados, pp. 154-162.

39 Ibidem, p. 176.

40 On peut penser notamment au Chili, voir les travaux de Jaime Valenzuela Márquez, 1999, pp. 575-615, et 2001 .

41 Elles sont le plus souvent ensevelies dans les Actas de cabildo, là où elles subsistent. 
défense de la Monarchie, le négatif de tout ce qui était célébré en ces jours de janvier $1711 .{ }^{42}$

L'exemple de Salta, qui fit imprimer la double relation des honras pour Philippe V et la proclamation de Ferdinand VI est encore plus illustratif. ${ }^{43} \mathrm{D}$ 'abord par son contexte: le gouverneur est en campagne contre les Indiens du Chaco lorsqu'il apprend la nouvelle de la mort de Philippe V (19 juin 1747). Il ne rentre en ville que le 23 juillet, les honras ont lieu le 27: le temps des préparatifs a été bref. L'essentiel de l'attention est reportée sur la proclamation, plus tardive, et qui est longuement décrite, accompagnée de ses festivités étirées sur une semaine. Autre tonalité, propre au XVIIIe, et qui nous intéresse plus directement, l'accent est mis sur la couleur locale. Parmi les titres dont on pare Ferdinand VI, apparaît celui de Inga. ${ }^{44} \mathrm{Si}$ les jeux de cañas mettent en scène des españoles galanes et des Turcs, certains cavaliers se sont déguisés en Indiens, les uns «imitando a los Indios Aucaes, cuya nación (aunque barbara) no dexa de usar algun genero de vestuario, si bien es rissible por su despreciable corte y traza, no obstante, como esta quadrilla havia convertido sus toscas mantas en costosas persianas y ricos encages, era a la vista airosamente agradable». On aurait pu se croire sur la scène d'un théâtre italien! Mais il y avait aussi de la tragi-comédie, car la dernière compagnie «imitaba a los indios Mocobies, cuya nación havita estas immediatas fronteras y es la mas barbara, cruel y sangrienta [...]. Esta quadrilla era la que más propiamente imitaba su nación, assi en los ademanes y trage como en lo ridiculo de sonajillas y cascabelillos de monte con que adornan sus caballos». ${ }^{45}$ Dans l'exactitude et l'attention portées à l'imitation on sent l'importance que revêt l'ennemi vital, au-delà de la dérision libératrice.

La complexité de cette relation à l'Indien de guerre, dans le cadre de la jura, qui devient tout à la fois catharsis, expression de loyalisme et occasion d'entraînement guerrier éclata le dernier jour des festivités à Salta. Il s'agissait de "hacer vistoso alarde de las estratagemas, arte y maximas que usan los Indios barbaros de esta frontera en la astuta guerra». On installa, en vis-à-vis, sur deux côtés de la place, une «tolde-

42 Orozco, Juan Felipe de: Relación de la plausible real solemnidad con que esta ilustre y leal Ciudad de Durango, cabeza de esta Nueva Viscaya, celebró la Jura de nuestro principe de Asturias, el Señor D. Luis Fernando [...], Mexico, 1711, description dans Tovar de Teresa, 1988, t. I, p. 47.

43 Reales exequias que celebró la Ciudad de Salta.

44 Ibidem, p. 32.

45 Ibidem, p. 35. 
ria [...] formada con mucha propriedad de troncos y ramas», où on installa une cinquantaine d'Indiens tobas et mocobies - les seuls authentiques indigènes «conviés» aux célébrations-, et une estancia de españoles. Les Indiens feignent d'attaquer alors que surgit une troupe d'Espagnols. S'en suivent captures d'enfants et massacres simulés: avec quels yeux les contemporains voyaient-ils ces scènes d'un quotidien de frontière? Pensaient-ils encore à la jura? La relation tendue, tragique, avec l'Indien avait phagocyté tout le reste.

Les cérémonies, sur la frontière, ne pouvaient-elles avoir que ce goût amer? Ce serait oublier l'autre versant, non pas tellement le mythe du «bon sauvage» à la Rousseau -il ne pouvait guère avoir cours dans de tels univers-, mais celui du «sauvage domestiqué», à la jésuite... On dispose ici d'un document manuscrit exceptionnel, à l'occasion de la coronación de Charles IV, dans la province de Mojos — partie amazonienne de l'actuelle Bolivie. En 1790 les jésuites ne sont plus présents dans ce qui fut leurs missions, mais leur empreinte est restée, notamment à travers la maîtrise de la musique occidentale dont font preuve ces Indiens. En effet, de la proclamation de Charles IV nous sont parvenues — partitions et paroles en langue indienne -5 pièces musicales ${ }^{46}$ qui furent jouées par deux orchestres de 35 musiciens formés de flûtes, violons, violoncelles et harpes. On ne s'appesantira pas sur la portée baroque de tels métissages culturels.

L'analyse des textes des chansons révèle un climat apaisé, où domine la présence du gouverneur espagnol — héritier des jésuites- «Buenas noches Señor Don Lázaro de Ribera, queremos alegrarnos, hombres y mugeres, festejando al Señor D. Carlos IV». Le monarque est beaucoup plus lointain, presque en filigrane: «si D. Lázaro de Ribera no hubiera venido trayendonos noticia de él, no lo conocieramos, ni viéramos su retrato». Incidemment, on a là la confirmation de l'importance que l'effigie royale continue à avoir, comme incarnation du pouvoir absent, pour les populations américaines, et peut-être plus encore pour les indigènes: «la señal de que nuestro Rey y Reyna nos quiere(n) mucho es, que el gobernador nos ha traido sus estampas y retratos». Pour le reste, la représentation du pouvoir, héritée des jésuites, est toujours là: «aqui venimos a festejar a nuestro Rey por que Dios lo ha puesto en la tierra que como el nos govierne [...]. Dios lo ha hecho capitan de toda la tierra». On ne s'attendait pas à retrouver une telle profession de foi universaliste dans ce recoin

46 Le tout transcrit par Cárdenas, 1977, pp. 759-773. 
des marges, et à cette date tardive. Il est vrai aussi qu'ailleurs des sentiments beaucoup plus réalistes pouvaient s'exprimer, au détour des proclamations.

\section{Les dividendes d'une présence}

Ne soyons pas dupe: ces cérémonies, même au fin fond de l'Amazonie, ces fêtes coûtaient fort cher «aux pauvres Indiens» comme aimaient à les appeler par ailleurs les administrateurs. Plus encore, s'agissant des festivités de Mojos, le manuscrit de la relation, les partitions de musique furent envoyés à Madrid accompagnés de remarquables gravures. On ne sait trop qui paya. Mais on devine qui entendait tirer profit, directement, de l'ensemble: le gouverneur espagnol. On pourrait multiplier les exemples de ce type.

En 1728-1729, l'Empire est embrasé par une succession de célébrations qui constituent un des points hauts festifs de la Monarchie au XVIIIe: les mariages princiers avec la famille régnante de Portugal. Il n'est alors guère de numéro de la Gaceta de Mexico $^{47}$ qui n'y fasse référence, s'agissant de l'Espagne, de Mexico, de Oaxaca, voire Tlaxcala où les caciques se pavanent vêtus à la mode française. Mais dans le flot une nouvelle attire le regard: les mariages ont été célébrés jusqu'à Zimapan. Les Indiens otomi de la région en ont sans doute tiré moins de profits, sinon de satisfaction, que leur alcalde mayor, qui a tenu à le faire savoir, par voie de presse. ${ }^{48}$

Les Archives des Indes, à Séville, ont conservé divers dossiers se rapportant à la demande présentée, vers 1799, devant le vice-roi, puis devant le Conseil des Indes, par Don Felipe Bartolome Ramirez, cacique de San Miguel el Grande, «sobre servicios que hizo en la jura de nuestro actual catolico Monarca». ${ }^{49}$ Ils sont accompagnés de deux magnifiques aquarelles —en fait elles sont quasiment semblables - qui représentent la proclamation de Charles IV à San Miguel, ou plus exactement la participation indienne à celle-ci, documents fascinants en soi ${ }^{50}$ Deux moments distincts y figurent: le serment prêté sur une estrade néo-classique, sous les portraits du couple royal, par le cacique habillé à la française, et s'apprêtant à jeter

47 Entre les numéros 6 et 20.

48 Gaceta de México, de février 1729, n 15.

49 AGI, Mexico, 1462 et 1796.

50 AGI, Mapas y Planos, Mexico, 434 et 434bis. 


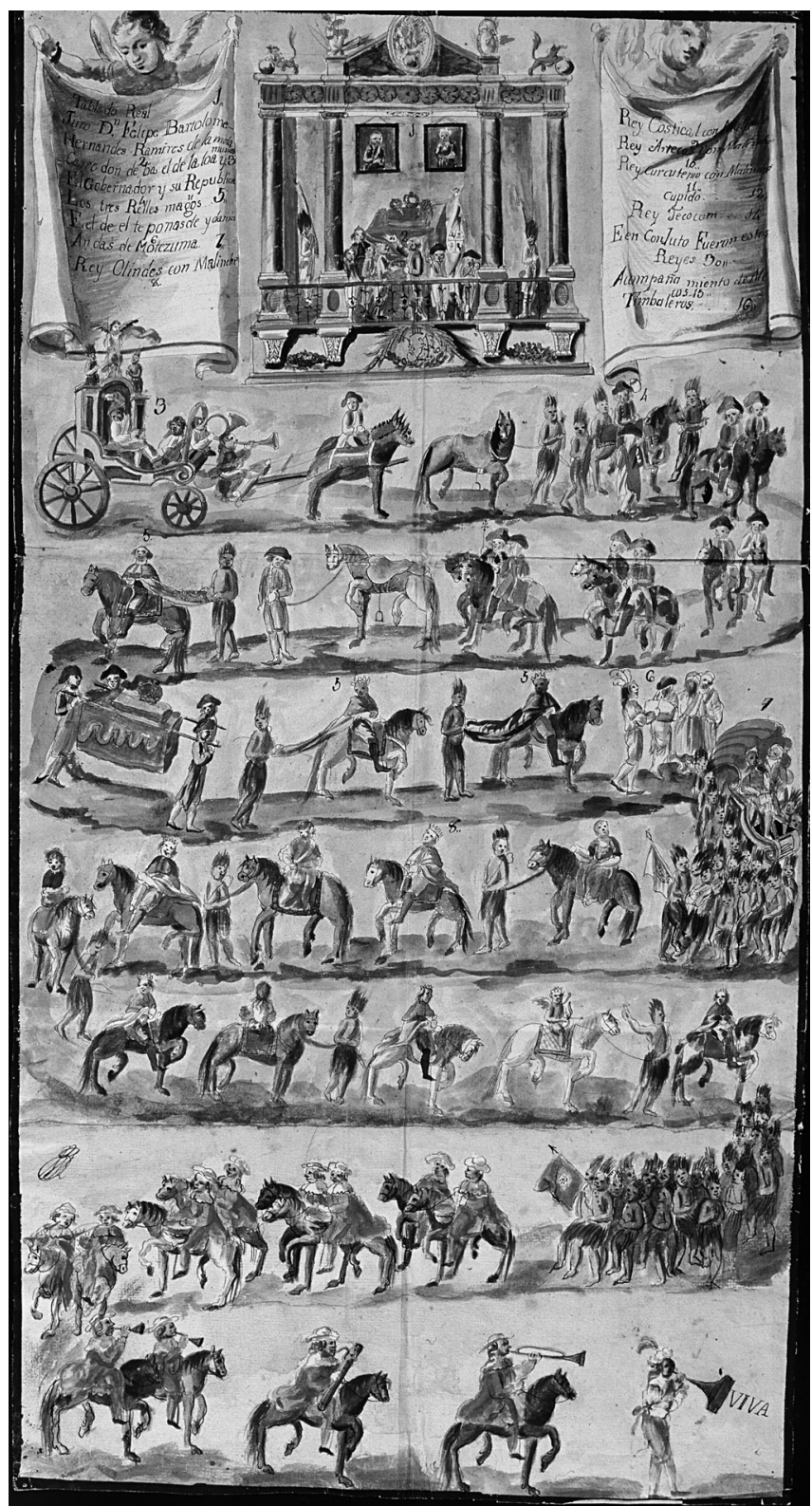

San Miguel el Grande: jura de Carlos IV por el cacique Felipe Bartolomé Ramírez (1791). AGI, Mapas y Planos, México, 434. 
des monnaies au menu peuple, et le défilé du cortège indien. Celui-ci apparaît avec une extrême minutie, il est ouvert et fermé par des musiciens, s'y succèdent gouverneurs indiens habillés à l'occidentale et troupes d'indigènes «à la chichimèque», danseurs avec leurs tambours (teponasqle), divers rois indiens (chacun avec sa Malinche). Au cœur du dispositif, portés sur des baldaquins, figurent Moctezuma et sa couronne. Et pour que tout cela n'ait pas une allure trop compassée, on y a associé un petit Cupidon à cheval, avec ses flèches, symbole de l'amour que ses sujets portent à Charles IV. On est au terme d'un processus multiséculaire, avec la «folklorisation» de la translatio imperii, ou donation de Moctezuma. La municipalité créole l'a bien compris, qui après avoir exécuté sur l'estrade sa propre jura, abandonne les lieux au cacique, sans grandes arrière-pensées. Ailleurs, c'est la milice créole qui se charge de mettre en scène, théâtralement, la double donation de Moctezuma et d'Atahualpa, comme à Granada, province de Nicaragua, en $1790 .{ }^{51}$

Le cacique de San Miguel avait-il, sur le moment, d'autres intentions, que d'afficher son loyalisme? En tout cas, près de huit ans plus tard, il entend envoyer son addition à la Monarchie. En échange des sacrifices consentis en 1791, il demande une double faveur: un blason se référant à l'action glorieuse de la jura — c'est pour cela qu'il fit exécuter les aquarelles, ou mapas_-, «y aplicarme dos sitios de ganado mayor en las tierras realengas que haya en las immediaciones de la villa de San Miguel el Grande, o en otro qualesquiera parage donde se encuentren». Etait-ce une preuve de cynisme que de monnayer son élan royaliste, en ce début du XIXe siècle? Le roi ne le considéra pas ainsi, puisqu'en 1804 il accorda au cacique les grâces demandées. Faut-il dire que sur les terres riches, animées du Bajio mexicain, la folklorisation allait de pair avec la monétarisation de la proclamation, et son appropriation individuelle, vers 1800 ?

Cette participation indienne aux diverses festivités dynastiques accrut leur caractère anecdotique: le statut de mineurs qui accompagnait les naturales les mettait à l'abri d'une trop grande retenue. Ainsi on vit se dresser, en 1714, sur la place de Mexico, une pyramide de victuailles

que franquearon caciques liberales

a la chusma de hambrientos macehuales. ${ }^{52}$

51 Pedro Ximena, 1974, pp. 133-137.

52 A l'occasion de la naissance du prince Felipe Pedro, cité dans Blanco Alfaro, 1996, p. 636. 
Sans doute avec du retard, mais inexorablement, la présence indienne, au cœur de la jura, montait aussi au Pérou, et plus précisément encore à Lima. Le dossier est connu, ${ }^{53}$ tient en trois dates: 1723 et les festivités pour le mariage du prince héritier, 1725 et la jura du même Luis I, enfin le couronnement de Ferdinand VI en 1748. L'élite créole et son amour de la patria chica fut comme le cheval de Troie, permit une meilleure mise en scène de l'histoire incaïque: par là s'engouffra l'aristocratie indienne de Lima. La Monarchie laissa faire, puisque la continuité avec la dynastie espagnole était affirmée: la jura permettait de théâtraliser la collaboration de la noblesse locale avec la Couronne.

Du moins ce fut la façade, jusqu'en 1748. En fait, les souvenirs ravivés faisaient mal. A propos de la conspiration avortée des Indiens de Lima en 1750, le vice-roi comte de Superunda devait écrire:

no me parece conveniente que en las públicas solemnidades de proclamación y nacimiento de principes se distingan los indios en gremio separado [...] y mucho menos que se les permita la representación de la serie de sus antiguos reyes con sus propios trajes y comitiva; memoria que en medio del regocijo los entristece, y pompa que les excita el deseo de dominar y el dolor de ver el cetro en otras manos que las de su nación; tres de los que hicieron aquella figura fueron cabezas las más altivas del levantamiento, y al tiempo de poner las reales insignias manifesto alguno con sus lagrimas el dolor que ocultaba el corazon. ${ }^{54}$

En fait le vice-roi devait, par la suite, oublier ses écrits (de 1751), et en 1759, à l'occasion de la jura de Charles III à Lima, les Indiens purent, encore, agir en pleine autonomie. Ceci nous permet de disposer d'un autre document exceptionnel, le seul imprimé décrivant uniquement la participation indienne à une proclamation. ${ }^{55}$ Par sa modestie même le texte mérite notre attention. La plume est prudente, remercie «una loable desunion» qui a séparé, pour la circonstance, «los naturales originarios» des autres «gremios», «deseosos siempre de no equivocar su amor con el de otra lealtad». ${ }^{56}$ Pour le reste, il a fallu réprimer tout excès (souvenir cuisant de 1748?): «moderando pues la extension de sus anhelos, hicieron el mayor sacrificio, en su resignación».57

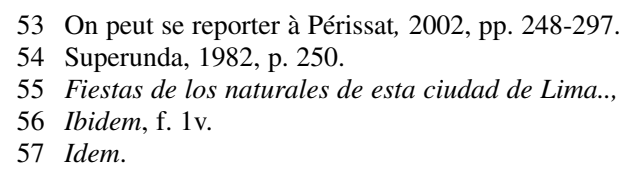


De façon significative, le texte n'évoque ni les cérémonies de jura, ni les festivités réalisées par les autorités et l'élite espagnoles, depuis août 1759. Sans le souci d'une quelconque continuité, ni même de donner son véritable sens à l'ensemble —-loyalisme à un nouveau souverain-, la description commence le 24 novembre, se limite à l'espace de temps festif accordé aux naturales. Ceux-ci ne sont d'ailleurs pas dupes: ils se savent otages de la culture dominante, et ils doivent lui donner des gages. En particulier, le 24 novembre, en ouverture, ils représentent, entre autres maquinas, «un corpulento galeon [...]. Representaba al que conduxo al Perú a sus conquistadores». ${ }^{58}$

Une fois ce geste d'allégeance accompli, la noblesse indienne peut, dans les jours qui suivent, distiller un peu de hardiesse. Et cela dans deux directions, en partie contradictoires, mais finalement complémentaires: elle souhaite se hisser à la hauteur des prérogatives de l'aristocratie créole, mais aussi manifester son identité propre. Le 25 novembre, les alcaldes indiens donnent un magnifique spectacle de toros, «vestidos decorosamente de golilla [...]; montados en generosos brutos [...]; hicieron el passeo de la plaza con la ceremonia acostumbrada». C'est un spectacle inédit, pour lequel il a fallu obtenir l'autorisation du vice-roi, puisqu'il s'agissait d'égaler la nación española. ${ }^{59}$

Le 28 novembre le message s'inverse. Les Indiens organisent un cortège ouvert par des danseurs «con todas las demas vestiduras y ornatos propios de el antiguo uso de la nacion», exécutant des danses guerrières de «antes de la conquista». ${ }^{60}$ Suit un char triomphal, où sont personnifiés, côte à côte «los doze incas [...], los principales conquistadores». ${ }^{61}$ Habilement l'auteur glisse sur les douze incas: n'oublions pas que Superunda est toujours là, comme vice-roi. Mais le message visuel n'en était pas moins clair et fort. On pourrait même penser qu'il était tronqué, et c'était inquiétant: les rois d'Espagne, successeurs des Incas sont quasiment absents. En fait, Charles III et son épouse étaient présents. Mais, autre hardiesse, ils se manifestaient à travers l'ersatz que constituait un jeune couple d'Indiens. ${ }^{62}$

58 Ibidem, fs. 2-3.

59 «Haviendose dignado la benignidad de S. E. de franquear a esta nación el honor de actuar esta función, con las prerrogativas y decoró con que las executa la española», Ibidem, fs. $4 \mathrm{v}-5 \mathrm{r}$.

60 Ibidem, f. 6v.

61 Ibidem, f. $7 \mathrm{v}$.

62 Ibidem, f. 8 r. 
Comme il fallait faire oublier quelques dérapages, le tout se terminait, comme il se doit, par un étalage de culture classique, d'emblèmes ayant maintes fois servi, mais toujours à propos et serviles. ${ }^{63}$ Peu importe, puisque, par ces cheminements prudents, l'élite indienne pouvait reconquérir un peu de l'espace social, voire politique qu'elle avait perdu depuis deux siècles.

\section{«Un air très vieux, languissant et funèbre» (G. de Nerval)}

Et si tout ceci nous ramenait à une irrépressible nostalgie? En matière de faits si complexes, il faut, à nouveau, citer longuement:

... es general y común en los indios la inclinación a sus antiguas bárbaras costumbres, y también a venerar la memoria de sus incas. No están todavia desimpresionados de sus errores, y así, aun en sus fiestas, mezclan siempre aparatos y canciones lúgubres con analogía a los sentimientos de que se halla penetrado su espíritu. Aunque son innumerables las Reales disposiciones dirigidas a civilizarlos, y arraigarles la Religión por cuantos medios dicta la piedad, y el más heroico celo, no se ha conseguido el fin deseado. ${ }^{64}$

Et si Jáuregui (et Superunda) n'embrassaient pas la totalité du phénomène? Si les Indiens ne pleuraient pas seulement leurs Incas — car alors, pourquoi ceux de Nouvelle Espagne ne se lamentaient-ils pas en pensant aux empereurs aztèques? - mais surtout un âge d'or perdu dont Manco Capac et ses successeurs ne seraient qu'une fraction? De là l'erreur de Jáuregui, sans doute obsédé -il écrit en 1784- par la barbarie de Tupac Amaru et autres rebelles: les reales disposiciones avaient, au contraire, si profondément imprégné les Indiens du XVIIIe que le principal objet de leur nostalgie était devenu la défunte dynastie —entendons par là «l'autrichienne»—, celle des Habsbourg. Plus encore: Charles Quint, héros conquérant, protecteur, civilisateur - tutélaire en un mot — était devenu, au lendemain de 1701, et avec la jura de Philippe «Quint», le cœur d'une vague nostalgique, recouvrant le continent indien, du Mexique au Pérou.

63 On pouvait lire sur le char triomphal, «El nuevo Mundo, que deseó en vano Alexandro, lo dió el Cielo a vuestros merecimientos, para que lo sujeteis, y governeis pacificamente, enseñandolo a reverenciar, y conocer al verdadero Dios», Ibidem, f. $11 \mathrm{r}$.

64 Jáuregui y Aldecoa, 1982, p. 193. 
Ici encore, la fête des naturales de Lima, en 1759, portera témoignage. C'est vrai, le cortège commence par des danses indigènes, on aperçoit les douze Incas. Mais quelle est l'image qui clôt le défilé? «En la espalda de la excelsa popa estaba pintado el Señor Emperador Don Carlos V», en souverain universel (avec les deux globes), supérieur en cela à Alexandre lui-même. Et la devise qui l'accompagnait était on ne peut plus claire: «Bona causa triumphat». ${ }^{65}$

Notons ici au passage l'importance de la continuité d'une dynastie (indigène) à l'autre (étrangère) qui imprègne les esprits, les expressions festives, voire monarchiques et religieuses des Péruviens (Indiens et créoles) depuis le XVIIe siècle au moins. Ce sentiment est tellement fort qu'il eut un effet de boomerang jusqu'à Madrid. En 1743, le grand ordonnateur du programme iconographique du Palais Royal, fray Martín Sarmiento écrivait:

Otra docena de adornos se me ofrece que sé que gustará a muchos, y en especial a los americanos. Siendo el imperio de México y del Perú las dos principales y más preciosas piedras de la Corona de su Magestad, no parecerá extraño que algunos de sus emperadores idólatras sirvan de adorno al Palacio, seis a su derecha y seis a su izquierda».

Ensuite le projet fut restreint, mais Moctezuma et Atahualpa contemplent aujourd'hui le ciel de Madrid depuis des lieux privilégiés. ${ }^{66}$

La résurgence (ou la persistance) de la symbolique habsbourg, de son héros, de son idéologie, notamment à travers l'iconographie, et dans le monde indien dépasse notre propos, restreint aux seules proclamations. ${ }^{67}$ Précisément tout ceci éclate au cours des cérémonies de 1701: partout, lorsque le portrait de Philippe V est présenté, il porte l'habit à l'espagnole, et surtout la toison d'or. On sait qu'à cette date Texcoco exhibe fièrement les armes données par le César. Bien sûr, à ce moment, et orchestré par les autorités, il y a le souci d'afficher une continuité, d'ailleurs servie par d'heureuses coïncidences: Charles et Philippe ont le même munéro, et ils sont tous les deux fondateurs d'une dynastie, et resplendissants de vertus guerrières.

Mais ces expressions de continuité durèrent peu: le temps de s'apercevoir que la dynastie Bourbon ouvrait aussi de nouvelles ères, que son

65 Fiestas de los naturales de esta ciudad de Lima, fs. 10v-11r.

66 Cité par Rodríguez G. de Ceballos, en Mínguez (ed.), 2007, pp. 188-189.

67 Voir aussi Calvo, septiembre-diciembre de 2003, pp. 23-41. 
centralisme se heurtait au localisme de plus en plus affiché. Ceci vaut sans doute pour les créoles. Qu'en pensaient les Indiens? En fait les concepts les intéressent peu: ils s'accrochent à leurs privilèges, à leurs mythes fondateurs, à leurs traditions, face aux pressions montantes (des grands domaines, du fisc royal). Un texte pourrait être symptomatique de leur état d'esprit, accroché à un souverain présent et intemporel à la fois: en 1735 les représentants de la communauté de Tecali écrivent: «usamos de nuestros recursos legales para libertarnos de tantas penciones [...], bien sabemos que tenemos Rey, alcalde Mayor y Justicia a quien obedecer como estamos promptos menos en el particular de recibirle sus repartimientos, pues tenemos una real y nobísima cédula de su Majestad Cathólica, que Dios le guarde, que nos favorece». ${ }^{68}$ Or, à ces divers niveaux, Charles Quint est présent, et les titulos primordiales ${ }^{69}$ fictions historiques du XVIIIe s'appuieront souvent sur son autorité.

Il y avait là un danger pour la nouvelle dynastie, qui risquait de se trouver dévalorisée dans la mise en perspective. Au fil des ans, ses thuriféraires surent s'en apercevoir, de chaque côté de l'Atlantique. En 17771779, l'Académie espagnole ouvrit un concours destiné à célébrer Philippe $\mathrm{V}$. Le vainqueur, originaire des Canaries, dressait un parallèle, mais en inversant les positions et les valeurs:

Carlos V, espléndido, esparcido, ostentoso; Felipe V, franco, moderado, modesto. Carlos retirándose porque la fortuna le dejaba; Felipe retirándose porque él despreciaba la fortuna; y con todo eso, Carlos se retiró a un Convento para vivir como religioso, y Felipe a un Palacio para morir como Principe. ${ }^{70}$

En 1790, à l'occasion de la jura de Charles IV à Granada (Nicaragua), le curé Pedro Ximena, andalou, exalte Philippe V et la dynastie Bourbon. L'Age d'Or est dans le présent: "¿Qué siglo mas venturoso para las Españas y Americas, que el actual décimo octavo? Desde sus primeros lustros se nos presenta glorioso». ${ }^{71}$ Mais de tels propos sont hors de l'orbite des Indiens, et sans doute aussi des créoles.

Quant à l'aigle bicéphale, symbole habsbourg, il reste récurrent tout au long du XVIIIe siècle encore. Il est présent sur les médailles frappées à

68 Taylor, 1999, t. II, p. 538.

69 Certains títulos sont signés «Callos quitoc» (Carlos Quinto). Voir, Noguez et Wood (coords.), 1998, p. 210.

70 Cité par Alfonso Mola et Martínez Shaw, 2000-2001, pp. 43-54, p. 50.

71 Pedro Ximena, 1974, p. 102. 
Lima en 1789, à l'occasion de la proclamation de Charles IV. L'aigle couronné, flottent sur l'océan, enserrant l'écus que Charles $\mathrm{V}$ donna à la ville, et encadré par les deux colonnes du Plus Ultra: veut-on plus de références impériales habsbourgeoises? $?^{72}$ Mais, dira-t-on, ce n'est pas ici un exemple indigène. Peut-être, mais par ailleurs nombre d'autres témoignages tendent à démontrer que les Indiens s'étaient approprié cette icône. Un tableau anonyme du XVIIIe, très certainement réalisé dans l'environnement de la noblesse indienne, met en scène les armées de Moctezuma et Cortés: audessus des Espagnols flottent les armes de Castille, au-dessus des Mexicas l'aigle bicéphale, sur fond pourpre. ${ }^{73}$ Au-delà, et jusqu'à aujourd'hui, cet emblème, du nord au sud du Mexique (du moins de la Sierra du Nayarit à Oaxaca) s'est intégré au quotidien, devient un motif de décoration vestimentaire. ${ }^{74}$

Nostalgie et esthétique archaïsante se soutenaient mutuellement, donnant aux juras auxquelles participaient les Indiens une tonalité particulière, alors même qu'elles s'étiolaient ou changeaient radicalement de sens dans le cadre hispanique. Cet ensemble de faits fut particulièrement sensible aux heures graves de 1808-1809, à travers l'Amérique: en 1808 pour l'avènement (?) de Ferdinand VII, en 1809 pour le serment d'obéissance à la Suprême Junte Centrale. On connaît le débordement de loyalisme de 1808, qui permet de retrouver la force d'un rituel multiséculaire qui tendait à s'alanguir (avec la jura de Charles IV, compassée, laïcisée notamment). ${ }^{75}$ Mais à Taretan (Michoacan), «la alegria y regocijo general y desaogo (de) sus anttes tristes corazones» furent tels que les habitants - en majorité indiens, ici- improvisèrent à l'instant une jura, promenant à travers toute la localité le portrait du roi, «entre festivos vivas, sonoros repiques». La proclamation formelle aura lieu une quinzaine de jours plus tard. ${ }^{76}$

Parce que des erreurs avaient été commises dans la gestion des juras au long du XVIIIe siècle, ${ }^{77}$ parce qu'il fallait éviter certains débordements

72 Médaille reproduite sur la couverture de l'ouvrage de Altuve-Febres Lores, 2001.

73 Reproduit dans Los pinceles de la historia, $\mathrm{n}^{\circ}$ de catalogue 67, p. 101.

74 Chez les Huicholes, parmi certains groupes de l'Etat de Oaxaca. Sur une gravure du XIXe, une indienne de Ayautla porte une cape où s'étale un magnifique aigle bicéphale. Garcia Cubas, Antonio: «Carta etnografica», 1885, reproduite dans p. 46. Aoyama, 2004, p. 46.

75 Ainsi à Puebla, Enciso y Mendez et Callejo y Saravia, Sinceras demostraciones de jubilo, $1808,26 \mathrm{pp}$.

76 Document communiqué par M. Augeron, AGN, Mexico, Historia, leg. 46, fs. 496-499.

77 Voir Calvo, otoño 2005. 
— comme celui de Taretan—, parce que l'heure était à une dramatisation sobre, le Conseil des Indes, à la fin de 1808, révisa totalement les modalités de la proclamation de la Junte. En fait, pour l'essentiel, la proclamationcommunion unanimiste était remplacée par un long serment de loyalisme à la Monarchie, prêté sur les Evangiles et le Christ, à titre individuel, au sein des diverses corporations qui constituaient la communauté, sans nécessité d'un rassemblement. Cette modalité fut respectée partout, et par (presque) tous. Mais à Huejotzingo, dans le Mexique central, où les caciques et les «républicas de naturales de todo el partido» se mêlaient aux «labradores, comerciantes, personas de distinción de la jurisdicción» on maintint pour l'essentiel l'ancien rituel, avec la construction d'un estrade située entre les casas reales et l'hôtel de ville; on y plaça un portrait du Souverain, déposé là par les autorités et par les «gobiernos y republicas de naturales de los pueblos». C'est là qu'eut lieu la jura sous sa forme ancienne, au cours de laquelle on retrouve les gestes de la théophanie — portrait dévoilé au moment culminant - abandonnés depuis des décennies. La prestation de serments eut lieu ensuite, dans un espace clos. ${ }^{78}$

Il y a donc bien comme une fascination du monde indien pour la jura. Faut-il s'étonner que lorsqu'en 1820 Mexico célèbre sa dernière proclamation royale - celle de la constitution libérale-, un auteur anonyme (Fernández de Lizardi?) choisisse de la décrire à travers les yeux —et les paroles-d'un indien? Cela lui permettait une ironie facile sur les humbles des campagnes, mais aussi de souligner combien il était facile de toucher la fibre sensible avec une mise en scène, quelques gestes appropriés, des mots grandiloquents et peu familiers. On obtenait un enthousiasme à peu de frais:

¡Viva el Coestetución grata,
noestro gra Fernando Siete,
y do Jua Ruiz de Podaca! ${ }^{79}$

\section{La défense d'un espace rituel conquis}

Il serait cependant imprudent de rester sur cette note (créole) d'une jobardise indienne qui passerait aussi par leur engouement pour tout

78 Document communiqué par Beatriz Rojas, AGNM, Historia, 417.

79 Attribué à Fernández de Lizardi, 1981, pp. 251-257. 
l'apparat de la jura. Il est par ailleurs inutile d'insister sur la persistance du sentiment loyaliste indigène pendant et après les guerres d'Indépendance.

Situons la proclamation royale dans cette double perspective. En 1701, au moment crucial de son possible renouvellement, les indiens ont compris qu'elle pouvait devenir un instrument. Pour les élites indiennes, elle prend place dans leur stratégie de reconquête d'un espace politique: ils peuvent d'abord singer les élites créoles, et finir - comme à Huejotzingo en 1809- par lui imposer leur pratique ritualisée. Bien sûr, ce sont des victoires qui tiennent dans un verre d'eau... Mais elles ont d'autant plus d'importance que les créoles désertent sur ce terrain: ni les vertus chevaleresques, ni même Moctezuma ne sont plus à l'honneur au début du XIXe siècle. ${ }^{80}$ Pour «la chusma de macehuales», après tout, de médaille cueillie au vol en pyramide de victuailles, la jura entrait dans la gestion de leur survie et leurs divertissements, bien sûr à titre exceptionnel.

Finalement, au bout de trois siècles, la jura dans sa pédagogie sommaire mais efficace, restait adaptée aux aspirations de la population indienne, à qui elle contribuait à fixer des repères, de plus en plus complexes. Ainsi, en 1820, l'Indien fictif de Lizardi - ou tout autre publiciste- pouvait déclarer à sa femme, après avoir assisté à la proclamation de la Constitution:

\author{
... pero al güeno de tu esposo \\ si que no se le pasaba \\ el deseo de saber breve \\ de Costetución, boscaba \\ amigos que le dijieran, \\ piadosos que le enseñaran, \\ sos leyes e sus mandados». ${ }^{81}$
}

Il cherchait à connaître les arcanes de la Costetución après avoir, pendant des siècles tenté de déchiffrer les vertus du Prince. Rien n'avait changé? Peut-être la médiation augmentait-elle? Pour lire les qualités qui resplendissaient sur le visage du Souverain, avait-il besoin «d'amigos», de piadosos précepteurs? Ailleurs Lizardi lui-même écrivait, à propos des

80 Sinon, il suffit de rappeler le devenir d'un portrait emblématique de l'empereur aztèque, ayant appartenu à ses descendants, et finalement acheté, pour une somme dérisoire, par l'ambassadeur américain, en 1825, voir Bustamante, Diario historico, CD-1, 1822-1834, mai 1825, p. 28.

81 Fernández de Lizardi, J.J.: Obras. X. Folletos (1811-1820), p. 253. 
nouveaux droits que la Constitution accordait aux Indiens: «todo es jerigonza que no entienden, enigmas que no alcanzan a descifrar». ${ }^{82}$

Mais nous ne pouvons conclure par une pirouette cynique et facile à la façon de Cervantès et son rufian sévillan face au catafalque de Philippe II:

caló el chapeo, requirió la espada,

miró al soslayo, fuese, y no hubo nada.

Toute la documentation ici rassemblée nous apprend que la «religion royale» (civique si nous ajoutons tout ce qui tourne autour de la patria criolla) n'est pas un fait mineur. Ce fut une partie essentielle de la cohésion de la Monarchie sur plusieurs continents, à travers deux océans, et pendant 3 siècles. Bien entendu il y eut des variations: il est probable que le modèle espagnol évolua plus que l'américain. Une de nos hypothèses est que la sécularisation du Pouvoir au XVIIIe siècle s'accompagna d'une valorisation de la proclamation royale face aux honneurs funèbres qui sentaient l'encens. La jura, plus éloignée de l'air confiné de l'église offre plus de liberté à qui sait la saisir. Depuis les derniers temps de la Monarchie des Austrias les élites indiennes ont été soutenues par la Couronne, se sont vu ouvrir de nouveaux espaces (universités, Eglise). Pourquoi ne tenteraient-elles pas aussi de se construire une autonomie au cœur du rituel royal... Bien sûr, cela implique certaines réciprocités, et les caciques de Tlaxcala, de San Miguel el Grande fêteront la dynastie bourbon en habits à la française, verseront leur tribut au souvenir de la Conquête.

C'est ces mêmes Indiens —ou leurs descendants- qui participeront au soulèvement de Tupac Amaru, à celui de Hidalgo. Mais personne ne nous garantira qu'ils avaient le sentiment de se battre contre le roi d'Espagne: Tupac Amaru s'en prenait d'abord à l'administration locale, les rebelles du Bajío mexicain défilaient sous l'étendard de la Vierge de Guadalupe, en rien hostile a la Monarchie. Plus tard encore, un autre Habsbourg (Maximilien) trouva dans les communautés indigènes mexicaines de fidèles soutiens. C'est une autre histoire? C'est la suite de l'Histoire.

Recibido el 16 de diciembre de 2009

Aceptado el 28 de octubre de 2010

82 Ibidem, p. 405. 


\section{Bibliografía}

Aclamación y pendones que levanto la muy noble y coronada Ciudad de Los Reyes, por el Catolico y Augustissimo rey D. Carlos II, Lima, 1666.

Alfonso Mola, Marina: «Fiestas en honor de un rey lejano. Proclamación de Felipe V en América», XIV Coloquio de Historia Canario-Americana (2000), Las Palmas de Gran Canaria, Edición del Cabildo de Gran Canaria, 2002, CD, 2149-2158.

Alfonso Mola, Marina et Martínez Shaw, Carlos: «Los elogios de Felipe V de 1779», Trocadero, 12-13, Cádiz, 2000-2001, 43-54.

Altuve-Febres Lores, Fernán: Los Reinos del Perú, Apuntes sobre la monarquía peruana, segunda edición, Lima, Dupla Editorial, 2001.

Annuas de las missiones de el Colegio de la Compañia de Jesus de Guanajuato, transcription de Salvador Covarrubias Alcocer (texte inédit).

Blanco Alfaro, José Joaquín: El lector novohispano: una antología de la literatura mexicana colonial, México, Cal y arena, 1996.

Bustamante, Carlos María de: Diario histórico de México, CD-1, 1822-1834, Vázquez, Josefina Zoraida y Hernández Silva, Héctor Cuaúhtemoc (eds.), México, CIESAS/El Colegio de México, 2002.

Calvo, Thomas: «Conocer a su rey y encarnar el poder: la difusión de la figura real en América hispánica (siglos XVI-XVIII)», Historias, 56, México, septiembre-diciembre 2003, 23-41.

Calvo, «La jura de Ferdinand VI à Guadalajara (1747): de la religion royale à la festivité», Takwá, 8, Guadalajara (México), otoño 2005, 67-92.

Cárdenas, Inmaculada: «Los festejos en la provincia de Mojos, con motivo de la coronación de Carlos IV», Anuario de Estudios Americanos, XXXIV, Sevilla, 1977, 759-774.

Cervantes de Salazar, Francisco: México en 1554 y Túmulo imperial, edición, prólogo y notas de O'Gorman, Edmundo, séptima edición, Mexico DF, Porrúa, 1991 [1560].

Códice Osuna, Edición de Luis Chávez Orozco, Mexico, Instituto Indigenista Interamericano, 1947.

Chimalpáhin, Domingo: Las ocho relaciones y el memorial de Colhuacan, paleografía y traducción de Tena, Rafael, 2 vols., Mexico DF, Consejo Nacional para la Cultura y las Artes, Serie Cien de México, 1998.

Chimalpáhin, Diario, Mexico, Consejo Nacional para la Cultura y las Artes, Colección Cien de Mexico, Conaculta, 2001.

Enciso y Mendez, Joaquín Luis et Callejo y Saravia, Josef Rafael de: Sinceras demostraciones de jubilo, con que el Real y Pontificio Seminario Palafoxiano de S. Pedro y S. Juan de la Ciudad de la Puebla de los Angeles, (...) concurrió a celebrar la solemne Proclamación de nuestro Augusto Soberano el 
PROCLAMATIONS ROYALES ET INDIENS AU XVIIIE SIÈCLE

Señor Don Fernando VII de Borbon, El Amado, México, 1808, folleto de $26 \mathrm{pp}$.

Fernández de Lizardi, José Joaquín: Obras. X. Folletos (1811-1820), Recopilación, edición y notas de Palazón Mayoral, María Rosa y Fernández Arias, Irma, Mexico, UNAM, Instituto de Investigaciones Filológicas, 1981.

Fiestas de los naturales de esta ciudad de Lima y sus contornos, en celebridad de la Exaltación al Trono de S. M. el Señor Don Carlos III Nuestro Señor, s. 1., s. d., 13 fs.

Flores Galindo, Alberto: Buscando un inca. Identidad y utopía en los Andes, Mexico, Consejo Nacional para la Cultura y las Artes/Grijalbo, Serie Claves de América Latina, 1993 [1988].

González Acosta, Alejandro: Crespones y campanas tlaxcaltecas en 1701, México, Universidad Nacional Autónoma de México (UNAM), Estudios de Cultura Literaria Novohispana 14, 2000.

Jáuregui y Aldecoa, Agustín de: Relación y documentos de gobierno del virrey del Perú (1780-1784), Edición y estudio de Contreras, Remedios.

Madrid, Instituto «Gonzalo Fernández de Oviedo», CSIC, 1982.

López de Villaseñor, Pedro: Cartilla vieja de la nobilísima ciudad de Puebla (1781), México, UNAM /Instituto de Investigaciones Estéticas/ Imprenta Universitaria, 1961.

Menegus, Margarita y Aguirre, Rodolfo: Los indios, el sacerdocio y la Universidad en Nueva España, siglo XVI-XVIII, México, UNAM, 2006.

Mínguez, Víctor: Los reyes distantes: imágenes del poder en el México virreinal, Castellón, Universitat Jaume I, 1995.

Mínguez (ed.), Visiones de la Monarquía Hispánica, Castellón, Universitat Jaume I, 2007.

Mugaburú, Josephe et Francisco de: Diario de Lima (1640-1694), Lima, Imprenta. Vázquez, 1935.

Noguez, Xavier et Wood, Stephanie (coords.): De tlacuilos y escribanos, Mexico,

El Colegio de Michoacán y El Colegio Mexiquense, 1998.

Noticia de la Real aclamación que debio hazer, e hizo la muy noble, y muy leal Ciudad de los Angeles en la jura de la Cesarea y Catholica Magestad del Señor D. Philippo V, Rey de ambas Españas, s.l., s.d. (1702), s.p.

Oración funebre que en las solemnes excequias del mui alto y poderoso Señor Carlos tercero rey de España y de las Yndias celebradas en la Santa Yglesia Metropolitana de La Plata [...] dixo el Illmo Señor D. F. José Antonio de San Alberto, arzobispo de La Plata [...], Biblioteca Nacional de Madrid, mss. 20067.

Osorio, Alejandra: «The King in Lima: Simulacra, Ritual, and Rule in Seventeenth-Century Peru», Hispanic American Historical Review, 84, 3, Durham, N.C., 2004, 447-474. 
Peñuelas, Lic. Don Pablo: Sermon que en acción de gracias por la exaltación al trono de Nuestro católico monarca el señor Don Carlos IIII [...] predico en el real de la Purissima Concepción de Catorze el [...], Mexico, 1791, 14 pp.

Périssat, Karine: Lima fête ses rois (XVI-XVIIIe siècles). Hispanité et américanité dans les cérémonies royales, Paris, L'Harmattan, 2002.

Reales exequias que celebró la Ciudad de Salta, provincia del Tucuman, en las Indias occidentales, los dias 27 y 28 de julio de 1747 a la difunta Magestad de Nuestro Catholico Rey, y Señor don Phelipe Quinto, et Festivas demostraciones y afectuosos leales cultos que en obsequio de la feliz. Exaltacion al Trono de nuestro Catholico Rey y Señor Don Fernando Sexto que Dios guarde, en su dichosissima aclamación y juratributó la ciudad de Salta, provincia del Tucuman el las Indias occidentales, actuadas en el dia ocho de octubre de mil setecientos quarenta y siete años, y continuadas hasta el dia quinze de dicho mes y año, s.l., s. d., 1-13 et 15-46.

Reina Aoyama, Leticia: Caminos de luz y sombra. Historia indígena de Oaxaca en el siglo XIX, México, CIESAS-CDI, 2004.

Relaciones históricas de los siglos XVI y XVII, Madrid, Sociedad de Bibliófilos Españoles, 1896.

Rodríguez G. de Ceballos, Alfonso: «Las series icónicas pintadas de los emperadores incas en el siglo XVIII y su continuidad en la Monarquía hispánica», en Mínguez (ed.), Visiones de la Monarquía hispánica, 2007, 188-189.

Rojas, Beatriz (comp.): Documentos para el estudio de la cultura política de la transición. Juras, poderes e instrucciones. Nueva España y la Capitanía General de Guatemala, 1808-1820, México, Instituto Mora, 2005.

San José, Fray Calixto de, Tupac Inca: «Exclamación de la nación indiana», dans Testimonios, cartas y manifiestos indígenas (Desde la conquista hasta comienzos del siglo XX), Selección, prólogo, notas, glosario y bibliografía de Martin Lienhard, Caracas, Biblioteca Ayacucho, 1992, 240-254.

«Somptuoso, festivo, real aparato en que explica su lealtad la siempre Noble, Ilustre, Imperial y Regia Ciudad de Mexico [...] en la aclamación del mui soberano y poderoso principe D. Philippo Quinto [...]», Biblioteca Nacional de Madrid, ms. 21191/4, 4 avril 1701.

Soto González, Enrique: Fiestas reales y pontificias en Patzcuaro, Patzcuaro, CREFAL, 1991.

Superunda, Conde de: Relación de gobierno. Perú (1745-1761), Madrid, CSIC, 1983.

Taylor, William: Ministros de lo sagrado. Sacerdotes y feligreses en el México del siglo XVIII, 2 ts. Zamora, Michoacán, El Colegio de Michoacán, 1999.

Tovar de Teresa, Guillermo: Bibliografía Novohispana de Arte. Impresos mexicanos relativos al arte del siglo XVIII, México, Fondo de Cultura Económica, 1988. 
Valenzuela Márquez, Jaime: «De las liturgias del poder al poder de las liturgias: para una antropología política de Chile colonial», Historia, 32, Santiago de Chile, 1999, 575-615.

Valenzuela Márquez, Las liturgias del poder. Celebraciones públicas y estrategias persuasivas en Chile colonial (1609-1709), Santiago de Chile, DIBAM, Estudios de Cultura Literaria Novohispana 14, 2001.

Ximena, Don Pedro: Reales exequias por el señor Don Carlos III rey de las españas, y Americas. Y real proclamación de su augusto hijo el Señor D. Carlos $I V$, por la muy noble, y muy leal ciudad de Granada, provincia de Nicaragua [...], Edición y notas de Manuel I. Pérez Alonso, Managua, Banco Central de Nicaragua, 1974, [1793]. 